\title{
Fabrication and characterisation of hybrid photodiodes based on PCPDTBT-ZnO active layers
}

Kettle, J.P.; Kettle, J.; Chang, S.W.; Horie, M.

\section{Microelectronic Engineering}

\author{
DOI: \\ 10.1016/j.mee.2015.05.006
}

Published: 31/05/2015

Peer reviewed version

Cyswllt i'r cyhoeddiad / Link to publication

Dyfyniad o'r fersiwn a gyhoeddwyd / Citation for published version (APA):

Kettle, J. P., Kettle, J., Chang, S. W., \& Horie, M. (2015). Fabrication and characterisation of hybrid photodiodes based on PCPDTBT-ZnO active layers. Microelectronic Engineering, 146, 105-108. https://doi.org/10.1016/j.mee.2015.05.006

\footnotetext{
Hawliau Cyffredinol / General rights

Copyright and moral rights for the publications made accessible in the public portal are retained by the authors and/or other copyright owners and it is a condition of accessing publications that users recognise and abide by the legal requirements associated with these rights.

- Users may download and print one copy of any publication from the public portal for the purpose of private study or research.

- You may not further distribute the material or use it for any profit-making activity or commercial gain

- You may freely distribute the URL identifying the publication in the public portal?
}

Take down policy

If you believe that this document breaches copyright please contact us providing details, and we will remove access to the work immediately and investigate your claim. 


\section{Fabrication and characterisation of hybrid photodiodes based on PCPDTBT-ZnO active layers}

J. Kettle ${ }^{1 *}$, S-W. Chang ${ }^{2}$, M. Horie ${ }^{2}$

1. School of Electronics, Bangor University, Dean St., Bangor, Gwynedd, Wales, UK

2. Department of Chemical Engineering, National Tsing Hua University, 101, Sec. 2, Kuang-Fu Road, Hsinchu, Taiwan 30013, ROC.

* Contact e-mail: j.kettle@bangor.ac.uk)

\section{Abstract}

We report the fabrication and characterisation of an organic- inorganic hybrid Photodiode (HPD) based on PCPDTBT and Zinc Oxide ( $\mathrm{ZnO}$ ) photoactive layers. The main benefit of using these materials is that multi spectral light sensing from the UV through to the Near Infrared is achieved, encompassing wavelengths $\sim 350 \mathrm{~nm}-870 \mathrm{~nm}$. To our knowledge, this is one of the widest range responses reported for an inorganic-organic hybrid photodiode. The evaluation of the technology shows the devices exhibit one of the lowest levels of dark currents reported for a HPD, but some limitations exist due to a low on-off ratio and non-linearity of the responsivity at low incident power. The stability of devices made with PCPDTBT:ZnO active layers is compared to more commonly reported P3HT:ZnO devices in dark and it is shown that using PCPDTBT substantially improves lifetime.

\section{Highlights}

- Wide photoresponse from UV to the NIR is achieved

- Device exhibits low dark current and high rectification ratio for a hybrid device

- Responsivity is measured and shown to be linear for incident power $>0.04 \mathrm{~W} / \mathrm{cm}^{2}$

- Improved lifetime observed with PCPDTBT active layer, when compared to P3HT-based devices 


\section{Introduction}

Organic or hybrid photodiodes (HPDs) using metal oxide acceptor materials could have a number of advantages over the inorganic technologies, including potentially low costs, solution processability and flexibility, which could enable photodiodes to be placed onto non-flat surfaces [1,2]. Previous reports of HPDs possess a reasonable on/off ratio of photocurrent during illumination when compared to the dark current (typically $>2$ orders of magnitudes) [3]. Another major advantage is that the absorption profile can be 'tuned' to absorb most visible wavelengths by altering the semiconductor inside the active layer within the active layer [4].

In recent years, Zinc Oxide $(\mathrm{ZnO})$ has been widely studied due to its intrinsic properties suitable for optoelectronic applications such as in hybrid devices with organic semiconductors such as solar cells and photodiodes [5]. With a wide direct bandgap of $\sim 3.4 \mathrm{eV}$ at room temperature, $\mathrm{ZnO}$ has been regarded as an excellent semiconductor material for UV detection and possesses an absorption profile that compliments many organic semiconductors. $\mathrm{ZnO}$ can be easily deposited at room- or relatively low temperatures to form thin layers by standard techniques such as sputtering [6], atomic-layer deposition [7] and pulsed-laser deposition [8]. The electron mobility is generally limited by surface roughness and carrier scatterings at grain boundaries; however, the electron mobility in $\mathrm{ZnO}$ has been demonstrated to reach up to $110 \mathrm{~cm}^{2} / \mathrm{Vs}$, when using an elevated substrate temperature during the growth step [9]. In most cases where $\mathrm{ZnO}$ is deposited onto substrates at room temperature, the mobility is measured to be around $1-5 \mathrm{~cm}^{2} / \mathrm{Vs}[10]$. This value still remains much higher than many organic materials which are used as the acceptor material in organic photodiodes. ZnO has also been used widely for the development of hybrid photovoltaics or photodiodes (HPDs). In photovoltaics, performances up to $0.11 \%$ have been reported for 'planar' devices, where the $\mathrm{ZnO}$ is deposited as a flat, uniform surface and up to $0.76 \%$ for devices made with ZnO nanowires, which create an interdigitated interface with the organic layer [11]. In addition, up to $2.0 \%$ has been reported for devices using $\mathrm{ZnO}$ nano-particles/crystals in a bulk-heterojunction configuration with an donor material such as Poly(3-hexylthiophene-2,5-diyl) (P3HT) [11]. Most work on hybrid devices has focused on photovoltaics and utilised organic semiconductors such as polyfluorene [12], $\mathrm{P} 3 \mathrm{HT}$ [11] or polyaniline [13]. Whilst the performance as photovoltaics is low, the potential as photo-diodes or detectors has not been fully investigated.

In this paper, the fabrication, development and characterisation of ZnO HPDs is reported using the polymer Poly[2,6-(4,4-bis-(2-ethylhexyl)-4H-cyclopenta $\left[2,1-b ; 3,4-b^{\prime}\right]$ dithiophene)-alt- 
4,7(2,1,3-benzothiadiazole)] (PCPDTBT). Devices are shown to possess one of the lowest levels of dark current for a HPD, though the on-off ratio is limited due to the low photoresponse of the device. However, the main benefit of using these materials to make photodiodes is that multi spectral light sensing is possible from the UV through to the Near Infrared, encompassing wavelengths $\sim 350 \mathrm{~nm}-870 \mathrm{~nm}$. To our knowledge, this is one of the widest response ranges reported for a Hybrid-photodiode. It is also one of the first reports of using a low band gap co-polymer for a hybrid device. It is shown that using PCPDTBT ensures wide photoresponse, and also enhances air stability when compared to HPDs manufactured using more commonly used materials such as P3HT.

\section{Experimental}

The structure of the OPD device is shown in the inset of Figure 1(a). OPD devices were initially prepared in a clean room environment using an $80 \mathrm{~nm}$ thick indium tin oxide (ITO) coated glass substrates $\left(R_{s}=16 \Omega /\right.$ square $)$ that were first cleaned using deionised water, acetone and isopropanol in an ultrasonic cleaner, then treated in a UV-ozone reactor. For this work, a bilayer structure was used which is the simplest device geometry for a HPD. In this device architecture, a layer of $\mathrm{ZnO}$ is first deposited onto the electrode substrate, followed by the deposition of a donor organic semiconductor and finally by a top electrode.

A $25 \mathrm{~nm}$ layer of Zinc Oxide ( $\mathrm{ZnO}$ ) was deposited using sputtering (Edwards) at a rate of $1 \AA \AA \mathrm{s}$ and annealed at $250^{\circ} \mathrm{C}$. The donor material used was Poly[2,6-(4,4-bis-(2-ethylhexyl)-4H-cyclopenta [2,1-b;3,4- $\left.b^{\prime}\right]$ dithiophene)-alt-4,7(2,1,3-benzothiadiazole)] (PCPDTBT), although in section 4, Poly-(3hexylthiophene-2,5-diyl) (P3HT) was also used. These were prepared and mixed with chlorobenzene solvent with a concentration of $15 \mathrm{mg} / \mathrm{mL}$, with thickness of $30 \mathrm{~nm}$. Samples were transferred into a nitrogen atmosphere glovebox $\left(\left[\mathrm{O}_{2}\right],\left[\mathrm{H}_{2} \mathrm{O}\right]<1 \mathrm{ppm}\right)$, where the donor material was applied by spincasting (1250rpm for 60 seconds). Both the $\mathrm{ZnO}$ and donor material thickness was optimised. No annealing of the PCPDTBT was conducted, but P3HT was annealed at $140^{\circ} \mathrm{C}$. Finally, thermal evaporation of the cathode was undertaken through a shadow mask to define the device area. This consisted of a $10 \mathrm{~nm}$ layer of molybdenum trioxide $\left(\mathrm{MoO}_{3}\right)$ and $200 \mathrm{~nm}$ of silver ( $\left.\mathrm{Ag}\right)$. The corresponding energy band diagram of the device is shown in Figure 1(b). The absorption profile of the PCPDTBT and ZnO is shown in Figure $1(\mathrm{c})$.

The photoresponse studies were made with a Keithley 2600 source-measure unit (SMU) under the excitation of a Newport spectra solar simulator and a calibrated reference cell from Newport spectra. Responsivity measurements were made by illuminating the top surface of the OPD at normal 
incidence. The OPD response was measured in photoconductive mode, so an external reverse bias is applied via a Keithley 2600 SMU and the current was measured using either the SMU or a lock-in amplifier with an optically chopped input signal.

\section{Photodiode characterisation}

Figure 2 shows the dark current and performance under $100 \mathrm{~mW} / \mathrm{cm}^{2}$ (AM1.5G) incident power for the fabricated PCPDPTBT:ZnO HPD. The solar cell performance under AM1.5G illumination is low, with a Power Conversion Efficiency (PCE) of $0.070 \%$. This is to be expected owing to the planar interface, which usually leads to lower performances than devices based on $\mathrm{ZnO}$ nanocrystals or vertically aligned $\mathrm{ZnO}$ nanowires, because of the smaller interfacial area between the polymer and acceptor [11]. However, this does compare closely with the 'record' efficiency for a planar HPD. Based on the data seen in Figure 2, the dark current of the PCPDTBT:ZnO HPD at OV bias is $1.71 \times 10^{-}$ ${ }^{2} \mathrm{~mA} / \mathrm{cm}^{2}$ and the device exhibits an on-off ratio of $\sim 150$ at $100 \mathrm{~mW} / \mathrm{cm}^{2}$. Minimization of dark current is imperative, as this limits the minimum detectable power and also the dynamic range of the HPD, as the on/off ratio can be enhanced by reducing the dark current [15]. When compared to other HPD devices in the literature, the HPD in Figure 2 exhibits relatively low dark current [16]. The likely reason for are twofold; firstly, the overall charge transfer through the device is reduced, as a result of the low interfacial area, as previous HPDs tend to use non-planar surfaces. And secondly, the recombination of charge carriers at ITO electrode is reduced due to the larger potential barrier of the $\mathrm{ZnO}$ valence band (many previous reports use Titanium oxide $n$-type layers). In addition to the lower dark current, using $\mathrm{ZnO}$ as the acceptor material enables photocurrent generation into the UV region, giving the HPD a wider optical dynamic range. In this device, the UV response will be in practice limited by the borosilicate glass substrate, which filters out light below $340 \mathrm{~nm}$, but ZnO absorbs strongly below $340 \mathrm{~nm}$, suggesting a UV transparent substrate such as sapphire will increase the range of response of this device even further. Below $380 \mathrm{~nm}$, PCPDTBT does not absorb, implying that any UV part of the spectrum would be absorbed only by the ZnO layer. Figure 1(c) shows the absorption profile of both the $\mathrm{ZnO}$ and PCPDTBT, layers demonstrating the wide absorption properties.

To study the influence under different light intensities, we recorded J-V characteristics under different illumination power from 25 to $100 \mathrm{~mW} / \mathrm{cm}^{2}$. Devices were measured straight after exposure and illumination was removed in-between measurements. The responsivity of a photodiode is defined as a ratio of output photocurrent (IPD) from the OPD to the incident light 
power $(\mathrm{P})$ from the light source, or $R(\lambda)=I_{P D} / P$. Shown in Figure 3 is the responsivity and photodiode current as a function of incident light intensity $\left(P_{I N}\right)$ using AM1.5G illumination under -1V bias. The behaviour is linear, except at lower intensities. Below $40 \mathrm{~mW} / \mathrm{cm}^{2}$, the device exhibits a decrease in $I_{P D}$, though for intensities greater than $40 \mathrm{~mW} / \mathrm{cm}^{2}, I_{P D}$ is directly proportional to incident power. This low light behaviour supports the view of other publications, which explained the effect due to electron trap saturation and limited charge transport due to the electron/hole mobility of the ZnO and PCPDTBT, respectively [17].

Overlaid on Figure 3 is the rectification ratio of the HPD as a function of incident power, obtained from plotting the diode equation under illumination and dark conditions. Under dark conditions, the rectification ratio is measured at 75 and at $100 \mathrm{~mW} / \mathrm{cm}^{2}$ was measured at 46 . Although the parameter is not regularly reported for HPDs, the rectification ratio at $100 \mathrm{~mW} / \mathrm{cm}^{2}$ under bias of $1 \mathrm{~V}$ is higher than many previous reports for HPDs. To obtain photodiodes with high rectification ratios, efficient charge injection through the PCPDTBT and ZnO layers under forward bias is needed. This was achieved by ensuring that the potential barriers between each layer was low, so the data supports the view that using an $\mathrm{MoO}_{3}$ hole transport layer and $\mathrm{Ag}$ electrode minimises this barrier, as ITO-ZnO is already known to form an Ohmic contact [11]. The quality of the polymer film can also influence the diode properties and previous reports from this group show that the mobility of this polymer is high when using hole only devices, when compared to materials such as P3HT [18]. Rectification ratio appears to increase with reduced intensity, in agreement with other reports [16]. It has already been reported that the generation of charge carriers lowers the resistance of the bulk via a photo induced doping effect, which contributes to the increased rectification ratio as a function of input power [16].

\section{Photodiode lifetime}

Whilst there are many advantages to using organic or hybrid photodiodes, as listed in section 1 , it is important to research the operational lifetime of the photodiodes. In Figure 4(a), the normalized photocurrent, measured at $-1 \mathrm{~V}$, of PCPDTBT:ZnO HPD is plotted as a function of operating hours. This device was non-encapsulated and stored in the dark in between measurements, which were conducted approximately every 24 hours. The photocurrent is relatively stable for more than $200 \mathrm{~h}$, but decreases exponentially thereafter. The on/off ratio decreases approximately linearly over the first 200 hours as a result of increasing dark current. As a comparison, a P3HT:ZnO HPD is shown in figure 4 also, which displays considerably worse lifetime. This is an interesting observation; PCPDTBT 
lifetime studies on photodiodes or solar cells have not been extensively reported, however, data from out laboratory suggests that PCPDTBT:PC ${ }_{61} \mathrm{BM}$ based solar cells exhibit worse stability than $\mathrm{P} 3 \mathrm{HT}: \mathrm{PC}_{61} \mathrm{BM}$ based solar cells.

The degradation mechanism for these types of photodiodes are numerous and complex and the difference in stability between the PCPDTBT:ZnO and P3HT:ZnO HPDs could therefore be due to a number of reasons. One likely cause is the due to greater UV absorption of PCPDTBT films than in P3HT. For PCBM-based solar cells, there is limited UV cut off from PCBM material as it is blended with the polymer, however, in these HPDs, the UV will be cut off by the $\mathrm{ZnO}$, so the polymer experiences low UV exposure. Therefore, PCPDTBT is less affected by UV degradation in the HPD configuration than in PCBM-based solar cells.

This could also be due to a change in polymer morphology; therefore, the surface morphology of the PCPDTBT and P3HT photodiodes were studied using an atomic-force microscope (AFM) prior to lifetime testing and after lifetime testing. Data is shown in table 1; a small difference in PCPDTBT morphology was observed, with the value of the maximum peak-to-valley fluctuation $\left(Z_{\max }\right)$ and surface roughness $\left(R_{A}\right)$ both increasing by $\sim 25 \%$. This compares to a much greater increase in the P3HT morphology ( $R_{A}$ increases by $63 \%$ and $Z_{\max }$ by $\left.33 \%\right)$.

The degradation could also be as a result of the $\mathrm{ZnO} /$ polymer interface due to $\mathrm{ZnO}$ degradation, as $\mathrm{ZnO}$ is also known to possess a level of instability, in particularly under illumination. $\mathrm{ZnO}$ films naturally exhibit $n$-type conductivity and its origin has been discussed in terms of native defects, such as oxygen vacancies and zinc interstitials $[20,21]$. In the case of $\mathrm{ZnO}$, it has been shown that oxygen vacancies in $\mathrm{ZnO}$ could be quenched upon chemisorbed air/oxygen exposure which reduces the carrier concentration, resulting in a field depletion of surface electrons and conduction band bending $[21,22]$. This has also been reported to increase the dark current of ZnO-based HPDs, which would lead to a reduction in on-off ratios in HPDs, as a result of $\mathrm{O}_{2}$ desorption from the $\mathrm{ZnO}$ [23]. This view supports the data in Figure 4(b), where on-off steadily reduces with time, primarily as a result of dark current increase. The AFM measurements in table 1 shows that the PCPDTBT active layer possesses much lower surface roughness, which suggests that the PCPDTBT molecules are slightly more densely packed, which could slow down the diffusion of oxygen and moisture to the ZnO-PCPDTBT interface. This may contribute to the improved stability for the PCPDTBT devices. As the $\mathrm{P} 3 \mathrm{HT}$ film is more crystalline, the film possesses deeper and wider gaps at the boundaries between individual grains. Therefore, the boundaries may also be vulnerable locations for oxygen to penetrate through the film [19], leading to degradation of the $\mathrm{ZnO}$ interface.

\section{Conclusion}


In this paper we have reported a hybrid photodiode made with structure of ITO-ZnO-PCPDTBT-

$\mathrm{MoO}_{3}-\mathrm{Ag}$. The benefit of this approach is that multi spectral light sensing is possible from the UV through to the Near Infrared, encompassing wavelengths $350 \mathrm{~nm}-870 \mathrm{~nm}$, which is one of the widest responses observed for an organic or hybrid photodiode. A dark current at $\mathrm{OV}$ bias of $1.71 \times 10^{-}$

${ }^{2} \mathrm{~mA} / \mathrm{cm}^{2}$ is observed, which leads to a low on-off ratio of $\sim 180$ at $100 \mathrm{~mW} / \mathrm{cm}^{2}$. Devices made with PCPDTBT show good air stability, which could be further improved using encapsulation.

\section{References}

[1] Campbell, I. H., \& Crone, B. K. (2009). A near infrared organic photodiode with gain at low bias voltage. Applied Physics Letters, 95(26), 263302-263302.

[2] Ng, T. N., Wong, W. S., Chabinyc, M. L., Sambandan, S., \& Street, R. A. (2008). Flexible image sensor array with bulk heterojunction organic photodiode. Applied Physics Letters, 92(21), 213303.

[3] Guo, F., Xiao, Z., \& Huang, J. (2013). Fullerene Photodetectors with a Linear Dynamic Range of 90 dB Enabled by a Cross-Linkable Buffer Layer. Advanced Optical Materials, 1(4), 289-294.

[4] Forrest, S. R. (2004). The path to ubiquitous and low-cost organic electronic appliances on plastic. Nature, 428(6986), 911-918.

[5] Ozgur, U., Hofstetter, D., \& Morkoc, H. (2010). ZnO devices and applications: a review of current status and future prospects. Proceedings of the IEEE, 98(7), 1255-1268.

[6] Jouane, Y., Colis, S., Schmerber, G., Leuvrey, C., Dinia, A., Lévêque, P., ... \& Chapuis, Y. A. (2012). Annealing treatment for restoring and controlling the interface morphology of organic photovoltaic cells with interfacial sputtered ZnO films on P3HT: PCBM active layers. Journal of Materials Chemistry, 22(4), 1606-1612.Ald

[7] Berry, J. J., White, M. S., Widjonako, N. E., Bailey, B. A., Sigdel, A. K., Gorrie, C. W., ... \& Olson, D. C. (2009, June). Mixed metal oxide systems for organic photovoltaics. In Photovoltaic Specialists Conference (PVSC), 2009 34th IEEE (pp. 001448-001451). IEEE.

[8] Bayraktaroglu, B., Leedy, K., \& Neidhard, R. (2008). Microwave ZnO thin-film transistors. Electron Device Letters, IEEE, 29(9), 1024-1026.

[9] Jin, J. D., Luo, Y., Bao, P., Brox-Nilsen, C., Potter, R., \& Song, A. M. (2014). Tuning the electrical properties of $\mathrm{ZnO}$ thin-film transistors by thermal annealing in different gases. Thin Solid Films, $552,192-195$.

[10]Huang, J., Yin, Z., \& Zheng, Q. (2011). Applications of ZnO in organic and hybrid solar cells. Energy \& Environmental Science, 4(10), 3861-3877.

[11]Lin, Y. Y., Chen, C. W., Yen, W. C., Su, W. F., Ku, C. H., \& Wu, J. J. (2008). Near-ultraviolet photodetector based on hybrid polymer/zinc oxide nanorods by low-temperature solution processes. Applied Physics Letters, 92(23), 233301-233301.

[12]Mridha, S., \& Basak, D. (2008). ZnO/polyaniline based inorganic/organic hybrid structure: Electrical and photoconductivity properties. Applied Physics Letters, 92(14), 142111.

[13]Ramuz, M., Bürgi, L., Winnewisser, C., \& Seitz, P. (2008). High sensitivity organic photodiodes with low dark currents and incr eased lifetimes. Organic Electronics, 9(3), 369-376.

[14] Kettle, J., Waters, H., Horie, M., \& Chang, S. W. (2012). Effect of hole transporting layers on the performance of PCPDTBT: PCBM organic solar cells. Journal of Physics D: Applied Physics, 45(12), 125102.

[15] Guo, F., Yang, B., Yuan, Y., Xiao, Z., Dong, Q., Bi, Y., \& Huang, J. (2012). A nanocomposite ultraviolet photodetector based on interfacial trap-controlled charge injection. Nature nanotechnology, $7(12), 798-802$.

[16] Yuan, Z., Yu, J., Ma, W., \& Jiang, Y. (2012). A photodiode with high rectification ratio based on 
well-aligned $\mathrm{ZnO}$ nanowire arrays and regioregular poly (3-hexylthiophene-2, 5-diyl) hybrid heterojunction. Applied Physics A, 106(3), 511-515.

[17]Waldauf, C., Schilinsky, P., Hauch, J., \& Brabec, C. J. (2004). Material and device concepts for organic photovoltaics: towards competitive efficiencies. Thin Solid Films, 451, 503-507.Song paper on stability

[18] Kettle, J., Horie, M., Majewski, L. A., Saunders, B. R., Tuladhar, S., Nelson, J., \& Turner, M. L. (2011). Optimisation of PCPDTBT solar cells using polymer synthesis with Suzuki coupling. Solar Energy Materials and Solar Cells, 95(8), 2186-2193.

[19] Majewski, L. A., Kingsley, J. W., Balocco, C., \& Song, A. M. (2006). Influence of processing conditions on the stability of poly (3-hexylthiophene)-based field-effect transistors. Applied physics letters, 88(22), 222108.

[20] Jin, J. D., Luo, Y., Bao, P., Brox-Nilsen, C., Potter, R., \& Song, A. M. (2014). Tuning the electrical properties of $\mathrm{ZnO}$ thin-film transistors by thermal annealing in different gases. Thin Solid Films, 552, 192-195.

[21] Lien, C. C., Wu, C. Y., Li, Z. Q., \& Lin, J. J. (2011). Electrical conduction processes in ZnO in a wide temperature range 20-500 K. Journal of Applied Physics, 110(6), 063706.

[22]Song, S., Hong, W. K., Kwon, S. S., \& Lee, T. (2008). Passivation effects on ZnO nanowire field effect transistors under oxygen, ambient, and vacuum environments. Applied Physics Letters, 92(26), 263109.

[23]Tromholt, T., Manor, A., Katz, E. A., \& Krebs, F. C. (2011). Reversible degradation of inverted organic solar cells by concentrated sunlight. Nanotechnology, 22(22), 225401. 


\begin{tabular}{|l|c|c|c|c|}
\hline & \multicolumn{2}{|c|}{ Pristine } & \multicolumn{2}{c|}{ Aged } \\
\hline & $\mathrm{R}_{\mathrm{A}}$ & $\mathrm{Z}_{\mathrm{MAX}}$ & $\mathrm{R}_{\mathrm{A}}$ & $\mathrm{Z}_{\mathrm{MAX}}$ \\
\hline PCPDTBT:ZnO & 0.36 & 3.89 & 0.45 & 4.89 \\
\hline P3HT:ZnO & 0.47 & 6.99 & 0.77 & 9.22 \\
\hline
\end{tabular}

Table 1: Surface roughness $\left(R_{A}\right)$ and maximum peak-to-valley fluctuation $\left(Z_{\max }\right)$ of pristine and aged PCPDTBT:ZnO and P3HT:ZnO devices. The measurements are made on the 'air' facing surface i.e. the polymer and show that P3HT undergoes a greater variation in morphology with time, than PCPDTBT 
(a)
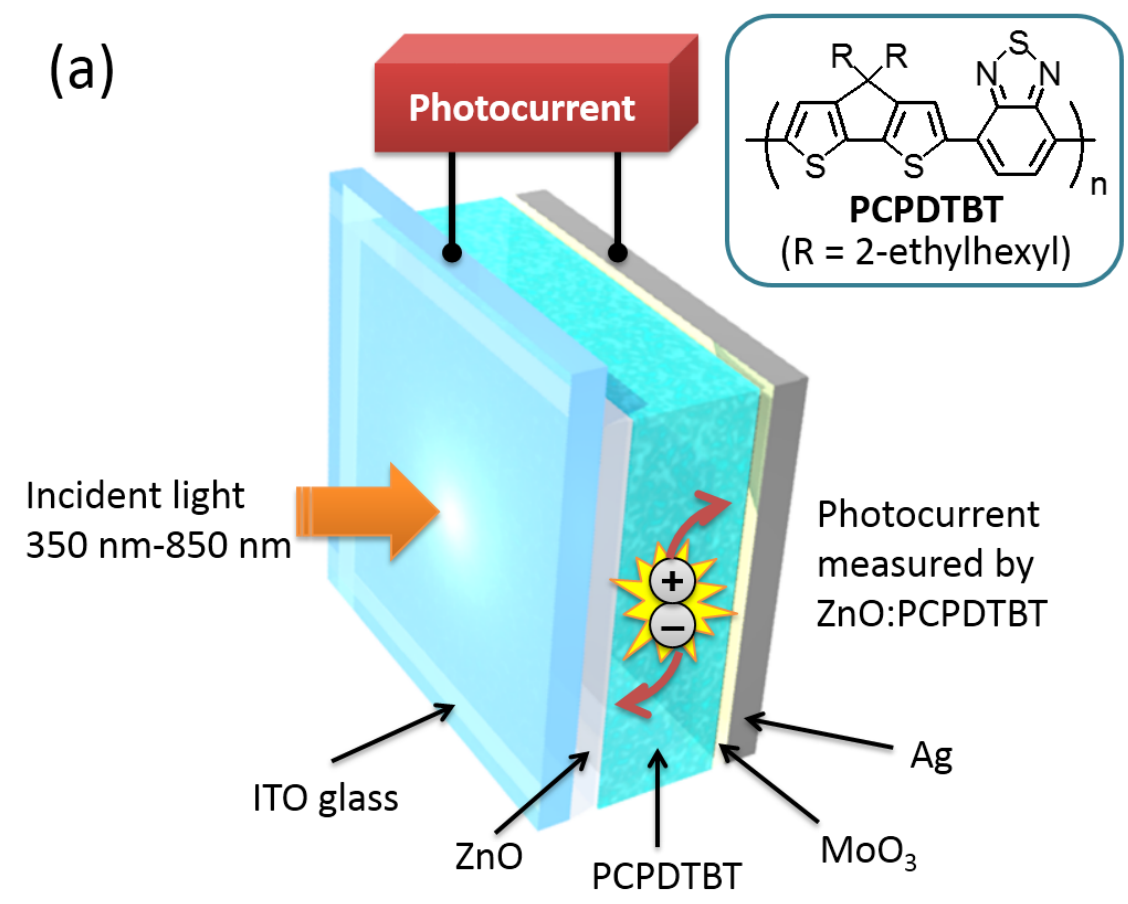

(b)

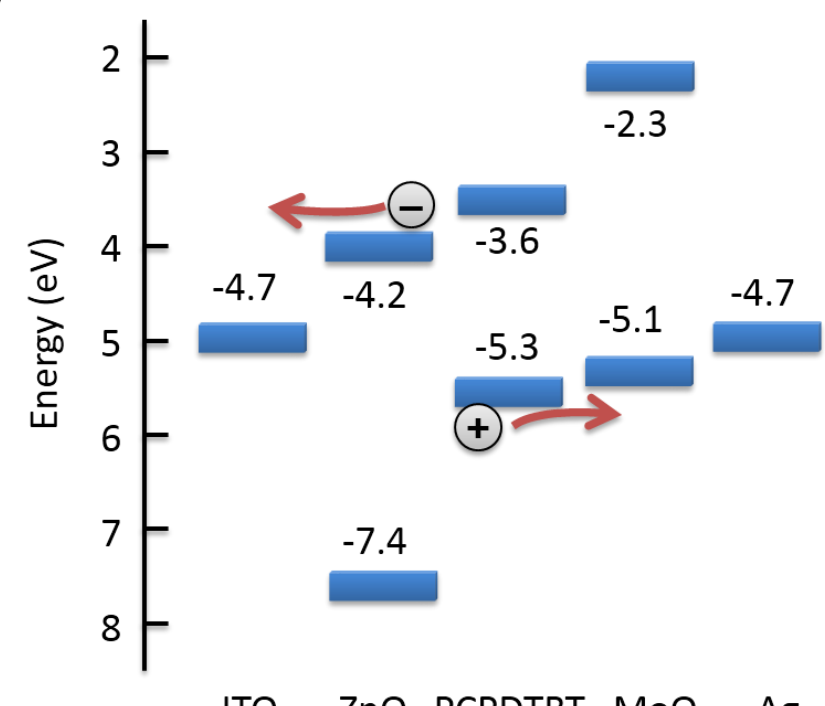

(c)

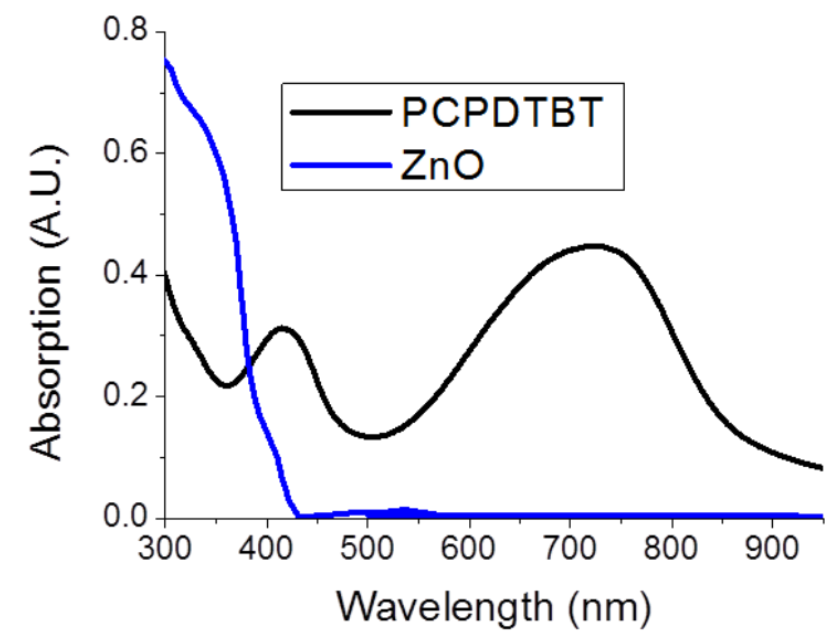


Figure 1 (a) Schematic of the photodiode and (b) Ideal flat band energy diagram for a PCPDTBT:ZnO photodiode(assuming $\mathrm{ZnO} E_{\mathrm{V}}=-7.4 \mathrm{eV}, E_{\mathrm{C}}=-4.2 \mathrm{eV}$ from [10]). Light is incident from the ITO side of the device. Other workfunction data is obtained from [14] (c) Absorption profile of PCPDTBT and ZnO layers

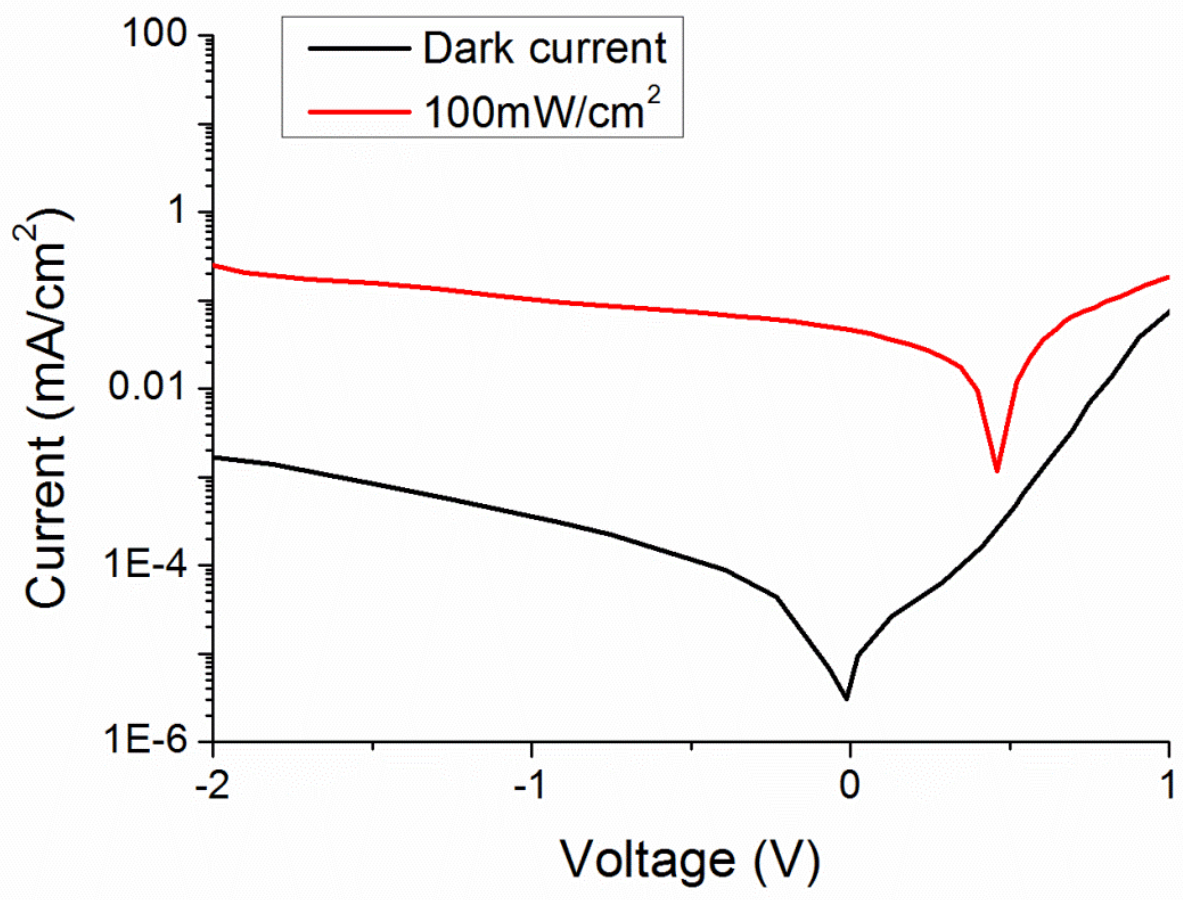

Figure 2: Current-Voltage characteristics of the PCPDTBT:ZnO photodiode under dark and with incident power of $100 \mathrm{~mW} / \mathrm{cm}^{2}$ 


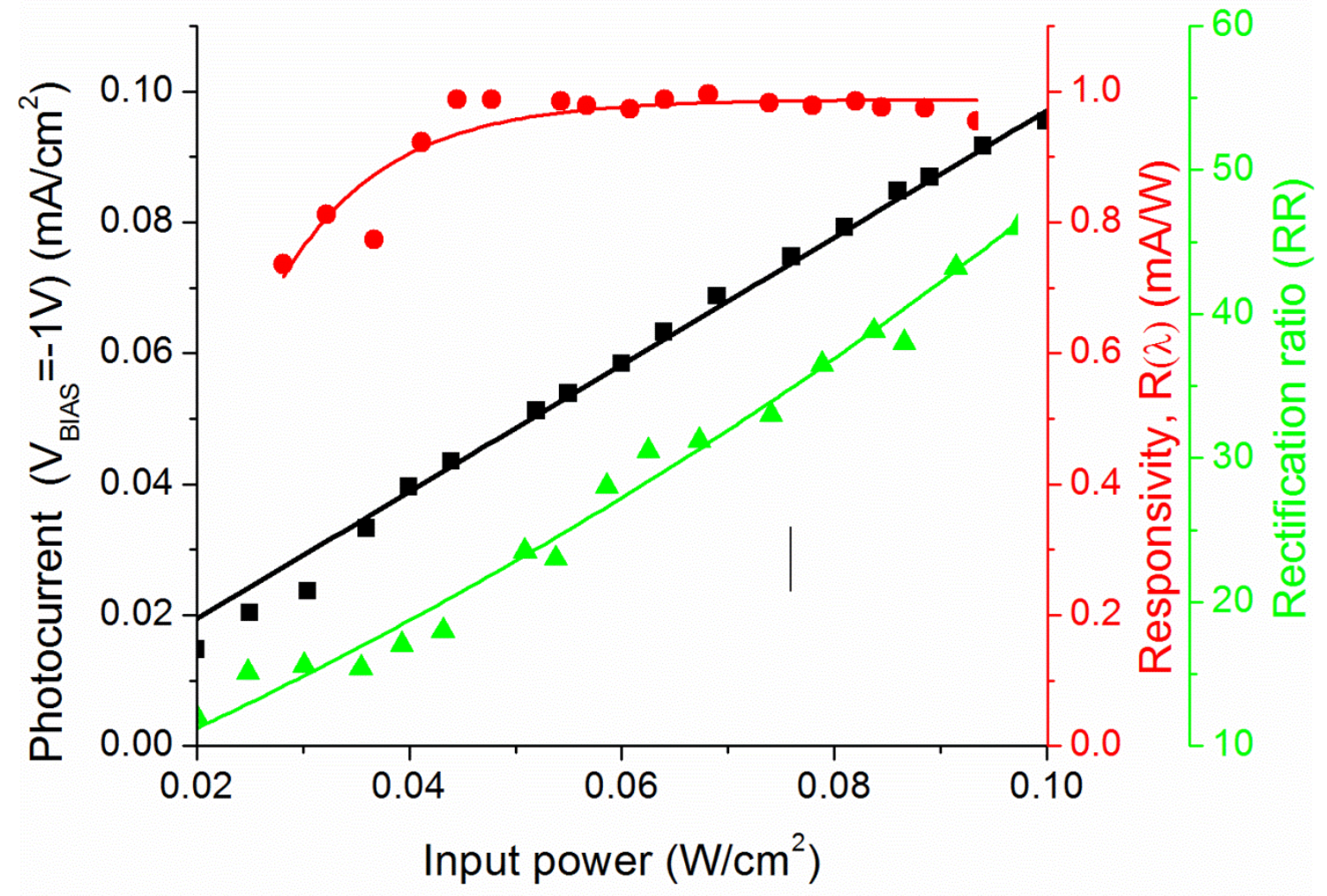

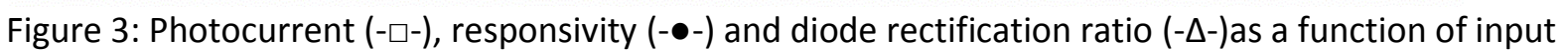
power, which was varied from $0.02 \mathrm{~W} / \mathrm{cm}^{2}$ up to $0.1 \mathrm{~W} / \mathrm{cm}^{2}$. The responsivity is not constant and is shown to decrease at lower intensities. 
(a)

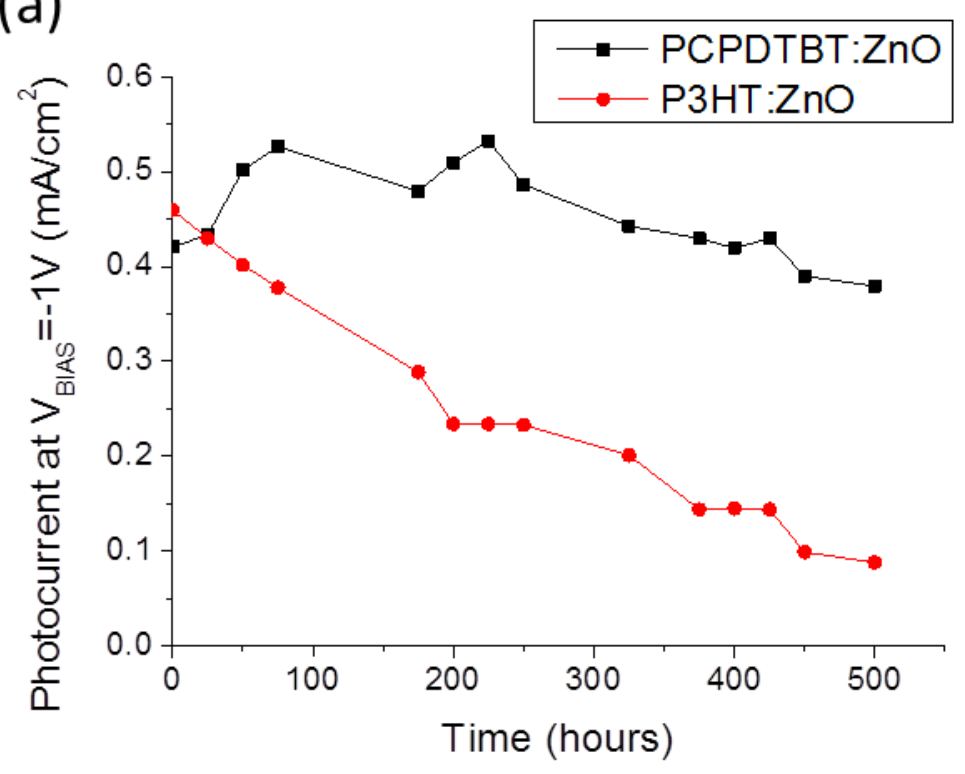

(b)

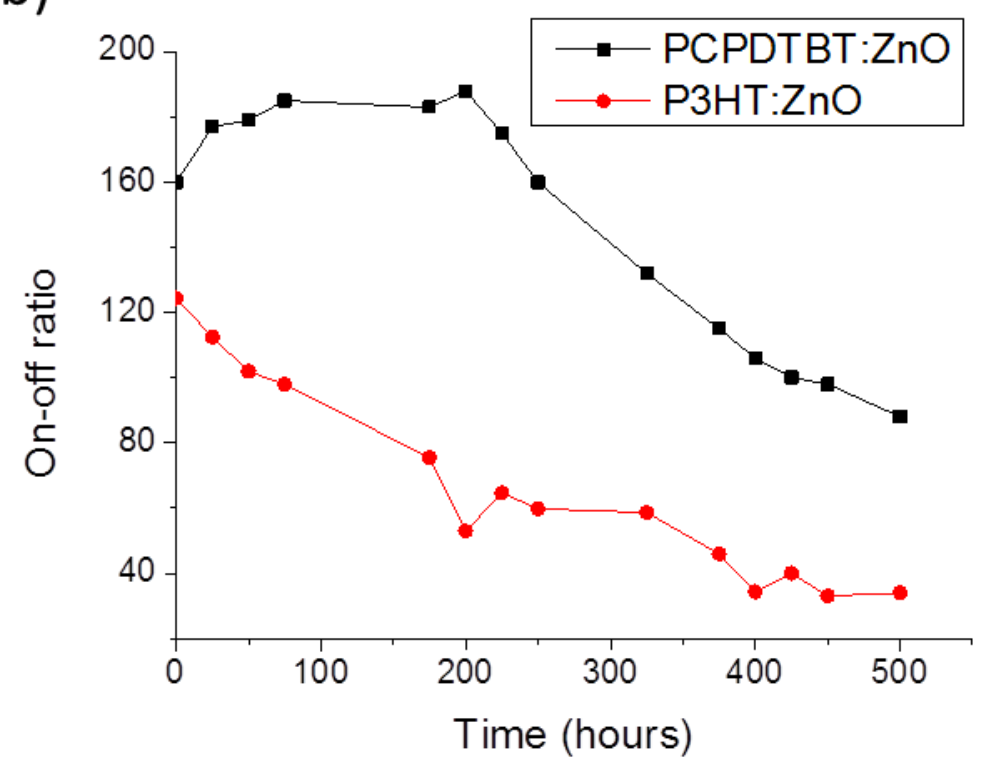

Figure 4: (a) Photoresponse at $\mathrm{V}_{\mathrm{BI} A \mathrm{~S}}=-1 \mathrm{~V}$ and (b) on-off ratio as a function of time as obtained under $100 \mathrm{~mW} / \mathrm{cm}^{2}$ irradiation. The applied bias was $-1 \mathrm{~V}$. 